\title{
PROPRIEDADES ACÚSTICAS (VELOCIDADE DE PROPAGAÇÃO E COEFICIENTE DE ATENUAÇÃO) DE SEDIMENTOS MARINHOS COLETADOS NAS PROXIMIDADES DA ILHA DO CABO FRIO, RJ
}

\author{
Helber Carvalho Macedo ${ }^{1}$, Alberto Garcia de Figueiredo $\mathrm{Jr}^{2}{ }^{2}$ e João Carlos Machado ${ }^{3}$ \\ Recebido em 5 janeiro, 2009 / Aceito em 25 junho, 2009 \\ Received on January 5, 2009 / Accepted on June 25, 2009
}

\begin{abstract}
Acoustic properties (wave propagation velocity and attenuation coefficient) of marine sediments are related to grain-size. In laboratory, an ultrasonic system of $2.25 \mathrm{MHz}$ was implemented to take measures of compressional wave propagation. Nine (9) piston-cores were collected, totaling twelve (12) meters of sediment. Before splitting the cores, approximately 2,550 measurements were taken. Results permitted to construct sound speed profiles and 3D attenuation coefficient diagram in the frequency domain. Interfaces between sedimentary layers were also identified. The highest value of sound speed $(1,752 \mathrm{~m} / \mathrm{s})$ was measured in medium sands. Sandy mud and consolidated mud registered the lowest values of this research (1,492 and 1,498 $\mathrm{m} / \mathrm{s}$, respectively), indicating a trend of increased $V p$ related to increased grain-size. The highest values of attenuation coefficient $(1,750$ and $1,550 \mathrm{~dB} / \mathrm{m}$, respectively) were measured in muddy sands and sandy mud, for the reference frequency 1.6 MHz. The lowest values were registered by fine sands and fluid mud (400 and $500 \mathrm{~dB} / \mathrm{m}$ ). These results indicate that cohesive sediments composed by heterogeneous mixtures have higher values of attenuation.
\end{abstract}

Keywords: acoustic properties, wave propagation velocity, attenuation coefficient, marine sediments.

RESUMO. Propriedades acústicas (velocidade de propagação de ondas e coeficiente de atenuação) de sedimentos marinhos, coletados por testemunhos de sondagem, foram correlacionadas à granulometria. Um sistema de medição destas propriedades, utilizando 2,25 MHz como freqüência nominal dos transdutores, foi montado em laboratório. Foram realizadas aproximadamente 2.550 medições acústicas ao longo de 9 testemunhos, totalizando $12 \mathrm{~m}$ de sedimentos. Os resultados obtidos permitiram construir perfis de velocidade da onda compressional $(V p)$ e diagramas em 3D do coeficiente de atenuação, em função da freqüência. Interfaces entre as camadas de sedimentos foram identificadas nos perfis de velocidade. Nas areias médias foram medidos os maiores valores de $V p(1.752 \mathrm{~m} / \mathrm{s})$, enquanto que os menores valores foram registrados na lama arenosa $(1.492 \mathrm{~m} / \mathrm{s})$ e na lama consolidada $(1.498 \mathrm{~m} / \mathrm{s})$, indicando uma tendência de aumento da $V p$ relacionada a um aumento da granulometria. Os maiores valores do coeficiente de atenuação, utilizando como referência a freqüência de 1,6 MHz, foram encontrados nas areias lamosas e nas lamas arenosas (1.750 e $1.550 \mathrm{~dB} / \mathrm{m}$, respectivamente). As areias finas e a lama fluida registraram os menores valores de atenuação: 400 e $500 \mathrm{~dB} / \mathrm{m}$, respectivamente. Estes resultados indicam que sedimentos coesivos compostos por misturas heterogêneas, têm valores mais elevados de atenuação.

Palavras-chave: propriedades acústicas, velocidade de ondas P, coeficiente de atenuação, sedimentos marinhos.

\footnotetext{
${ }^{1}$ Instituto de Estudos do Mar Almirante Paulo Moreira, IEAPM, Rua Kioto, 253, Praia dos Anjos, 28930-000 Arraial do Cabo, RJ, Brasil. Tel.: (22) 2622-9014; Fax: (22) 2622-9093 - E-mail: helber@predialnet.com.br/carvalho@ieapm.mar.mil.br

2Universidade Federal Fluminense, Laboratório de Geologia Marinha (LAGEMAR/UFF), Av. Litorânea s/n, Praia Vermelha, 24210-340 Niterói, RJ, Brasil. Tel.: (21) 2629-5938; Fax: (21) 2629-5931 - E-mail: alberto@igeo.uff.br

3 Universidade Federal do Rio de Janeiro, Programa de Engenharia Biomédica/COPPE, Cidade Universitária, Centro de Tecnologia, Bloco H, sala 327, Ilha do Fundão, 21941-914 Rio de Janeiro, RJ, Brasil. Tel.: (21) 2562-8578; Fax: (21) 2562-8591 - E-mail: jcm@peb.ufrj.br
} 


\section{INTRODUÇÃo}

A velocidade de propagação, a atenuação da onda compressional e a caracterização do tipo de sedimento que compõe 0 fundo marinho são propriedades físicas e parâmetros, entre outros, fundamentais à modelagem geoacústica do ambiente marinho (Hamilton, 1980; Richardson, 1997, 2002; Buckingham, 2000, 2004). Os resultados obtidos a partir de tais modelos podem ser amplamente aplicados em atividades relacionadas à operação de equipamentos sonar, à calibração da sísmica de reflexão utilizada em águas rasas, à caracterização geotécnica do leito marinho e à prospecção de minerais.

Neste contexto, o Laboratório de Geologia Marinha (LAGEMAR - UFF) e o Instituto de Estudos do Mar Almirante Paulo Moreira (IEAPM) uniram seus esforços e apoiaram o desenvolvimento desta pesquisa, que teve como principal objetivo analisar a propagação de ondas compressionais $(\mathrm{P})$ através de sedimentos marinhos de testemunhos de sondagem, correlacionando os valores da velocidade e do coeficiente de atenuação à granulometria.

Para atender a este propósito, foi utilizado um sistema experimental para medir e registrar a propagação de ondas $P$ em sedimentos (Macedo \& Figueiredo Jr., 2005). Este sistema foi montado no Laboratório de Ultra-Som (LUS) do Programa de Engenharia Biomédica da COPPE/UFRJ. As ondas mecânicas foram geradas a partir de pulsos elétricos convertidos em pulsos de onda $P$ por um transdutor. A freqüência utilizada para 0 transdutor foi de 2,25 MHz. Este sistema foi calibrado em água doce e em uma amostra controlada de sedimentos, composta por areia média, areia fina e argila (Macedo \& Figueiredo Jr., 2005).

Os testemunhos de sondagem foram coletados na plataforma continental do estado do Rio de Janeiro, nas proximidades da Ilha do Cabo Frio, na cidade de Arraial do Cabo. Foram coletados nove (9) testemunhos, totalizando cerca de 12,0 m de sedimentos.

Os resultados obtidos permitiram construir perfis de velocidade do som $V p$ e diagramas do coeficiente de atenuação, em função da freqüência. Estes dados foram associados à análise sedimentológica do material dos testemunhos, principalmente no que diz respeito à granulometria.

\section{METODOLOGIA}

\section{Dados pretéritos}

0 sistema de medições montado nesta pesquisa teve como base os experimentos realizados por Gorgas et al. (2002) e por Maa et al. (1997). Os primeiros executaram medições de $V p$ e atenuação em sedimentos coletados por testemunhos, na faixa de freqüência do ultra-som (400 kHz). Maa et al. (1997) mediram variações de valores de velocidade de ondas $P$, em função do tempo de consolidação dos sedimentos, na faixa de freqüência de 2,25 MHz.

Davis et al. (2002) produziram mapas com distribuição espacial indicando as propriedades acústicas do fundo marinho. Neste experimento foi utilizada uma metodologia de inversão, aplicada a dados de reflexão sísmica de alta resolução, onde os sinais são calibrados com medidas realizadas in situ e em testemunhos de sondagem.

No Programa REVIZEE (Figueiredo Jr. \& Madureira, 1999), foram construídos mapas de classificação de sedimentos a partir da análise de dados acústicos coletados por uma ecossonda EK-500 (Simrad), operando na freqüência de 38 kHz.

\section{Coleta de novos dados de velocidade, coeficiente de atenuação e granulometria}

Durante o processo de medição, os testemunhos coletados foram imersos em água para assegurar a continuidade de propagação da onda em todo o trajeto entre os transdutores emissor e receptor, colocados em lados diametralmente opostos do testemunho. 0 alinhamento entre os eixos de simetria dos transdutores foi mantido por meio da rigidez da ferramenta de perfilagem (Figs. 1 e 2). Deste modo, a onda de ultra-som propagou inicialmente na água, no PVC e, em seguida, no sedimento coletado.

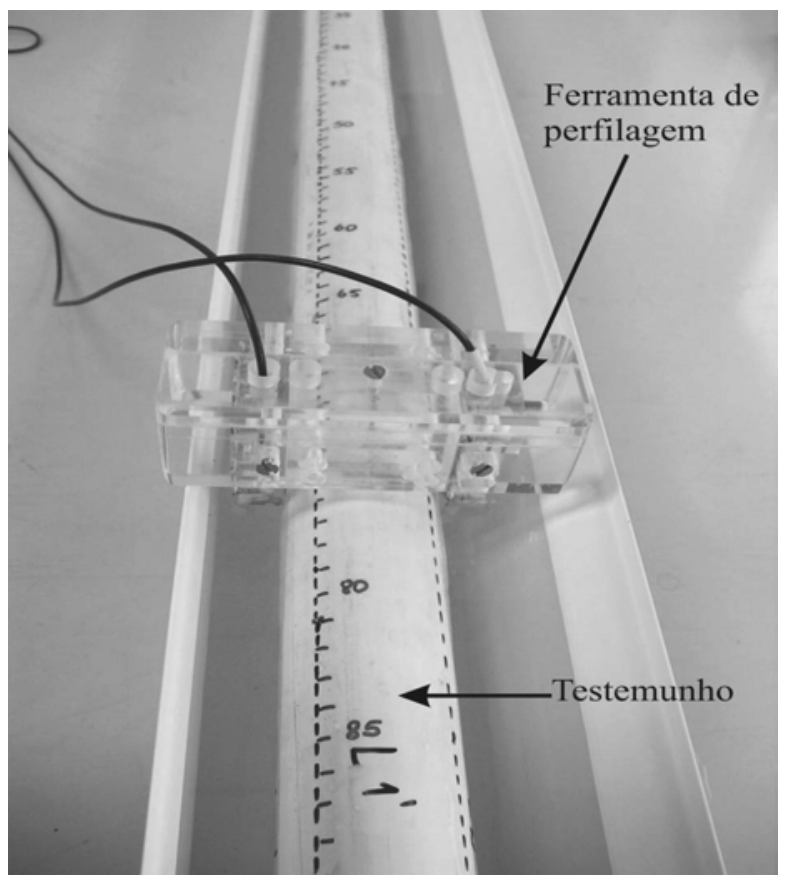

Figura 1 - Vista de topo do testemunho posicionado no tanque de medição. 


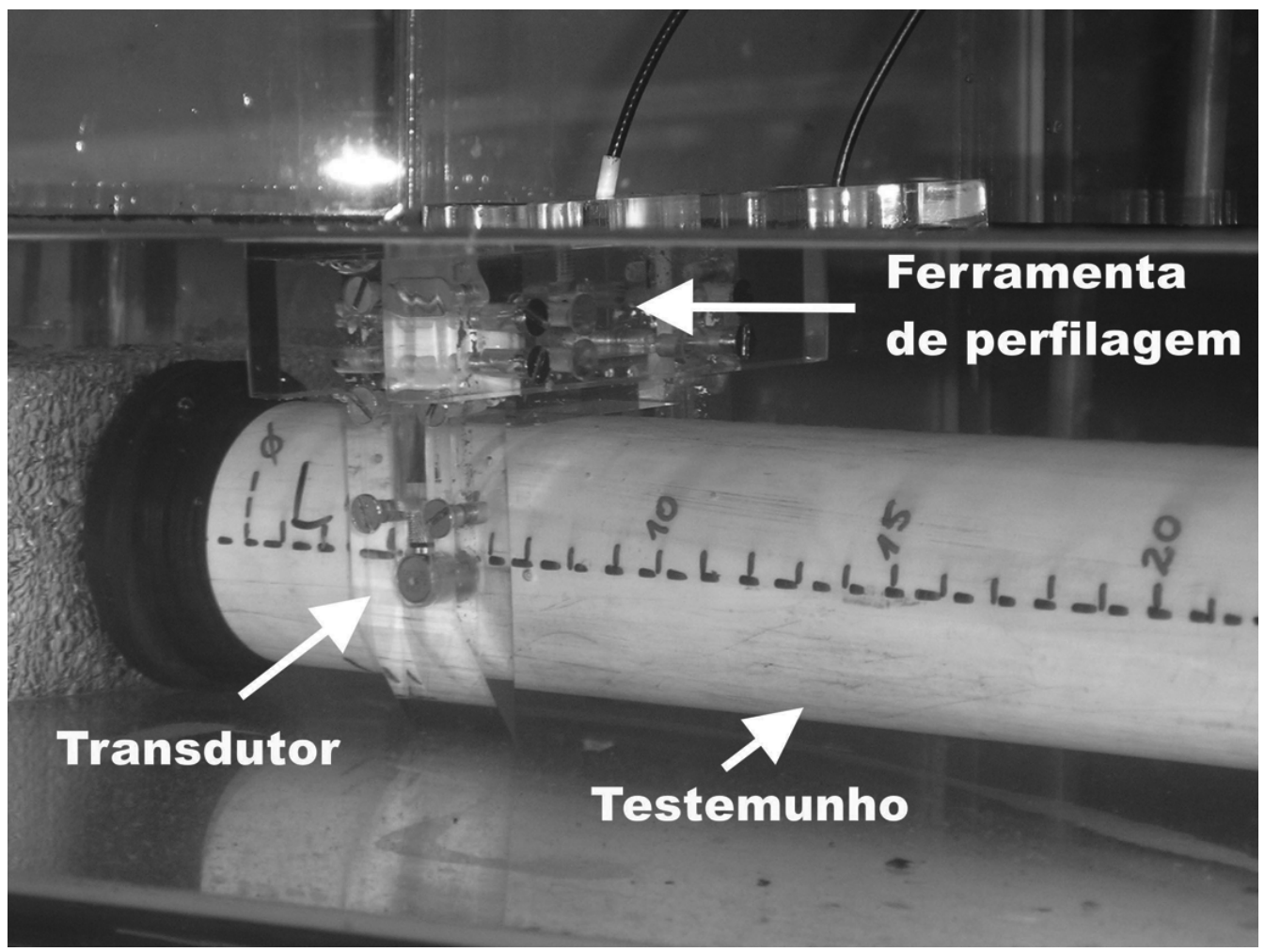

Figura 2 - Vista lateral do testemunho imerso no tanque com água.

As medições foram feitas em duas etapas e em planos ortogonais, de modo que cada posição ao longo do testemunho tivesse dois valores. Para cada testemunho foram construídos dois perfis de velocidade. 0 perfil 1, referente ao plano azul, e o perfil 2 para o plano vermelho. Estes planos estão defasados de $90^{\circ}$ (Fig. 3).

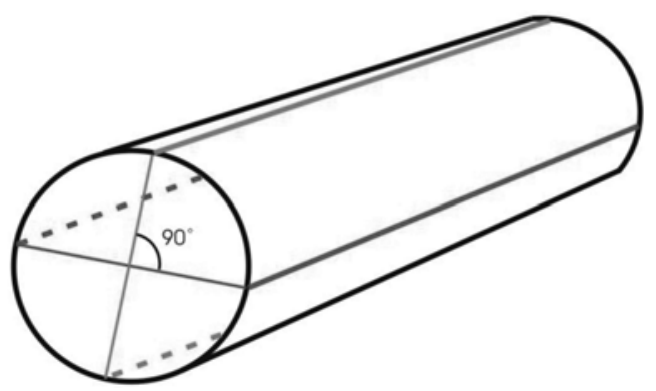

Figura 3 - Planos ortogonais representativos das linhas de medição no testemunho.

Foram realizadas aproximadamente 2.550 medições ao longo dos nove testemunhos coletados (Macedo et al., 2005). Os dados obtidos pelo sistema foram:

- o tempo decorrido durante a propagação do pulso no percurso entre 0 transdutor emissor (TR) e 0 transdutor receptor (RC), utilizado no cálculo da velocidade, expressa em $(\mathrm{m} / \mathrm{s}) ; \mathrm{e}$
- a razão entre os sinais elétricos, em volts e no domínio do tempo, recebidos pelo receptor (RC) em duas medições distintas. A primeira realizada em um tubo de PVC com água, idêntico ao testemunho. Já a segunda medição foi efetuada no testemunho com sedimento. Estes sinais elétricos foram digitalizados e convertidos em amplitudes espectrais no domínio da freqüência, utilizando-se 0 algoritmo da Transformada de Fourrier. 0 coeficiente de atenuação no sedimento, em decibel por metro $(\mathrm{dB} / \mathrm{m})$, foi obtido por meio do cálculo da razão entre as amplitudes dos sinais propagados na água e no sedimento, aplicandose 0 método da substituição de He \& Zeng (2001). Como referência, foi utilizada a atenuação medida na água, que tem seu valor próximo de zero (Hamilton, 1972).

Na aquisição e no processamento dos dados foram usados programas específicos desenvolvidos em ambiente LabView e MatLab, respectivamente.

Os resultados são apresentados em perfis de velocidade do som, para as duas linhas de medição (linha 1 e 2), e diagramas em 3D do coeficiente de atenuação (em função da freqüência), ambos em relação à posição correspondente ao longo do testemunho (a cada cm). 
Após as medições acústicas, os testemunhos foram abertos, fotografados e foi realizada a descrição sedimentológica com a finalidade de caracterizar e classificar o material. Para auxiliar a descrição dos testemunhos, foi efetuada a análise granuIométrica dos sedimentos, baseada no processo de peneiramento para sedimentos grossos, e no processo indireto de sedimentação e separação por pipetagem para os sedimentos finos; ambos descritos por Suguio (1973). A classificação dos sedimentos marinhos foi baseada no conjunto de dois métodos tradicionais, adaptados às condições da plataforma continental brasileira. 0 primeiro método segue a escala granulométrica de Wentworth (modificado de Krumbein \& Pettijohn, 1988), que classifica o sedimento de acordo com o tamanho do grão. As frações granulométricas dominantes e os teores de lama foram classificados utilizando o diagrama triangular de Shepard (1954).

Sete (7) tipos de sedimentos foram identificados: areias grossas, médias e finas, areia lamosa, lama arenosa, lama compactada (ou consolidada) e lama fluida. Para facilitar a descrição sedimentológica deste material, a legenda abaixo foi criada (Fig. 4), tendo como base símbolos geológicos padronizados (US Geological Survey, 2000).

Ao final, os resultados das medições com ultra-som (US) foram analisados e interpretados, sendo comparados às características dos sedimentos coletados.

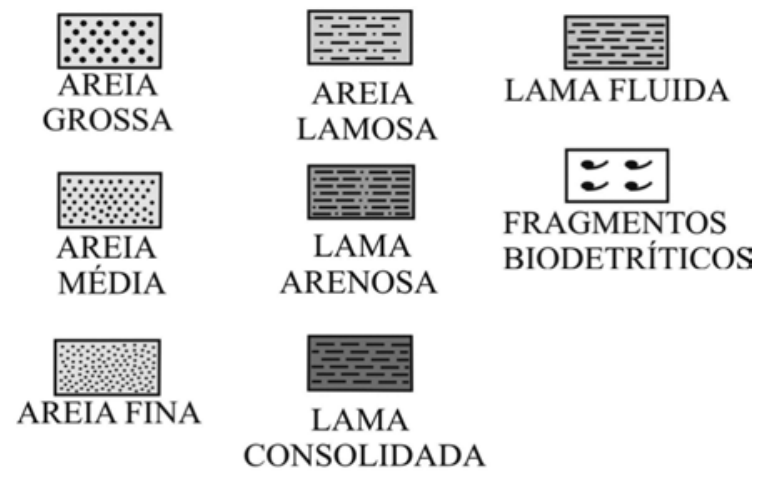

Figura 4 - Legenda com a identificação dos diferentes tipos de sedimentos encontrados nesta pesquisa.

\section{RESULTADOS}

Os resultados de velocidade são apresentados como gráficos (perfis) de velocidade do som (Vp) em função da posição no testemunho. A análise da variação do comportamento da onda sonora no meio foi realizada pela comparação do perfil $V p$ com a representação simplificada da granulometria. Os resultados de atenuação são apresentados em diagramas em 3D, em função da freqüência e também em relação à posição no testemunho
(Macedo, 2006). As Figuras 5, 6, 7 e 8 demonstram as variações de velocidade e atenuação observadas nos testemunhos 2 e 7 , escolhidos para este trabalho como os mais representativos.

0 testemunho 2 (Fig. 5), composto por areias finas e uma estreita camada de areia lamosa, apresenta um perfil sônico uniforme, com pequenas oscilações de valor. Na areia fina, a faixa de valores de velocidade está entre $1.635 \mathrm{~m} / \mathrm{s}$ (mínima) e $1.715 \mathrm{~m} / \mathrm{s}$ (máxima). No trecho de areia lamosa (entre os pontos 23 e $26 \mathrm{~cm}$ ), o registro sônico da linha 1 mostra uma queda acentuada de valor, atingindo $1.566 \mathrm{~m} / \mathrm{s}$. 0 registro do coeficiente de atenuação (Fig. 6) é regular e uniforme para as linhas $1 \mathrm{e}$ 2, indicando valores de cerca de $400 \mathrm{~dB} / \mathrm{m}$ para a freqüência de $1,6 \mathrm{MHz}$. Algumas variações pontuais são observadas ao longo do testemunho. Os valores máximos, cerca de $1.300 \mathrm{~dB} / \mathrm{m}$ para $1,6 \mathrm{MHz}$, são registrados nas linhas $1 \mathrm{e} 2$, entre os pontos $20 \mathrm{e}$ $27 \mathrm{~cm}$, coincidente com a camada de areia lamosa que está presente entre as areias finas. Portanto, respeitando-se as limitações de medições de atenuação, pode-se afirmar que nas areias finas os valores medidos estão na faixa de 400 a $700 \mathrm{~dB} / \mathrm{m}$, na freqüência de 1,6 MHz. Para a areia lamosa, os valores sobem para cerca de $1.300 \mathrm{~dB} / \mathrm{m}$, na mesma freqüência.

0 testemunho 7 (Fig. 7) tem em sua composição camadas de lama fluida e de lama consolidada (compactada). Nota-se uma estreita camada de lama arenosa nas proximidades do ponto $60 \mathrm{~cm}$, onde pode ser observada uma súbita elevação da $V p$, atingindo 0 valor máximo de $1.639 \mathrm{~m} / \mathrm{s}$. Desconsiderando esta exceção, o perfil sônico é uniforme e regular, com uma semelhança significativa entre as linhas 1 e 2 . Para as lamas consolidadas, os valores de velocidade medidos variaram de 1.508 a $1.600 \mathrm{~m} / \mathrm{s}$. As lamas fluidas forneceram medidas de 1.530 a $1.563 \mathrm{~m} / \mathrm{s}$. Quedas nos valores da velocidade são observadas nas linhas 1 e 2, associadas às interfaces das diferentes camadas. A primeira ocorre na transição de lama consolidada para fluida, no ponto $75 \mathrm{~cm}$, quando, em termos de valores médios, a velocidade cai de 1.550 para $1.537 \mathrm{~m} / \mathrm{s}$. Em seguida, é observada uma elevação da $V p$ no ponto $130 \mathrm{~cm}$, sucedida por uma queda, também para o valor de $1.537 \mathrm{~m} / \mathrm{s}$, no ponto $150 \mathrm{~cm}$. Um novo aumento na velocidade ocorre no ponto $160 \mathrm{~cm}$, atingindo o valor máximo de $1.575 \mathrm{~m} / \mathrm{s}$ no ponto $180 \mathrm{~cm}$ e caindo em seguida para $1.540 \mathrm{~m} / \mathrm{s}$, na base do testemunho.

0 registro do coeficiente de atenuação em ambas as linhas do testemunho 7 (Fig. 8) é irregular. Os maiores valores de atenuação são notados na linha 2, entre o topo e o ponto $80 \mathrm{~cm}$. Neste trecho 0 valor médio medido é de $900 \mathrm{~dB} / \mathrm{m}$, para a frequêencia de 1,6 MHz. Alguns pontos isolados chegam a atingir $1.000 \mathrm{~dB} / \mathrm{m}$. Do ponto 80 até 0 ponto $170 \mathrm{~cm}$, os valores são 


\section{TESTEMUNHO 2 - VELOCIDADE DE PROPAGAÇÃO DA ONDA $P$}

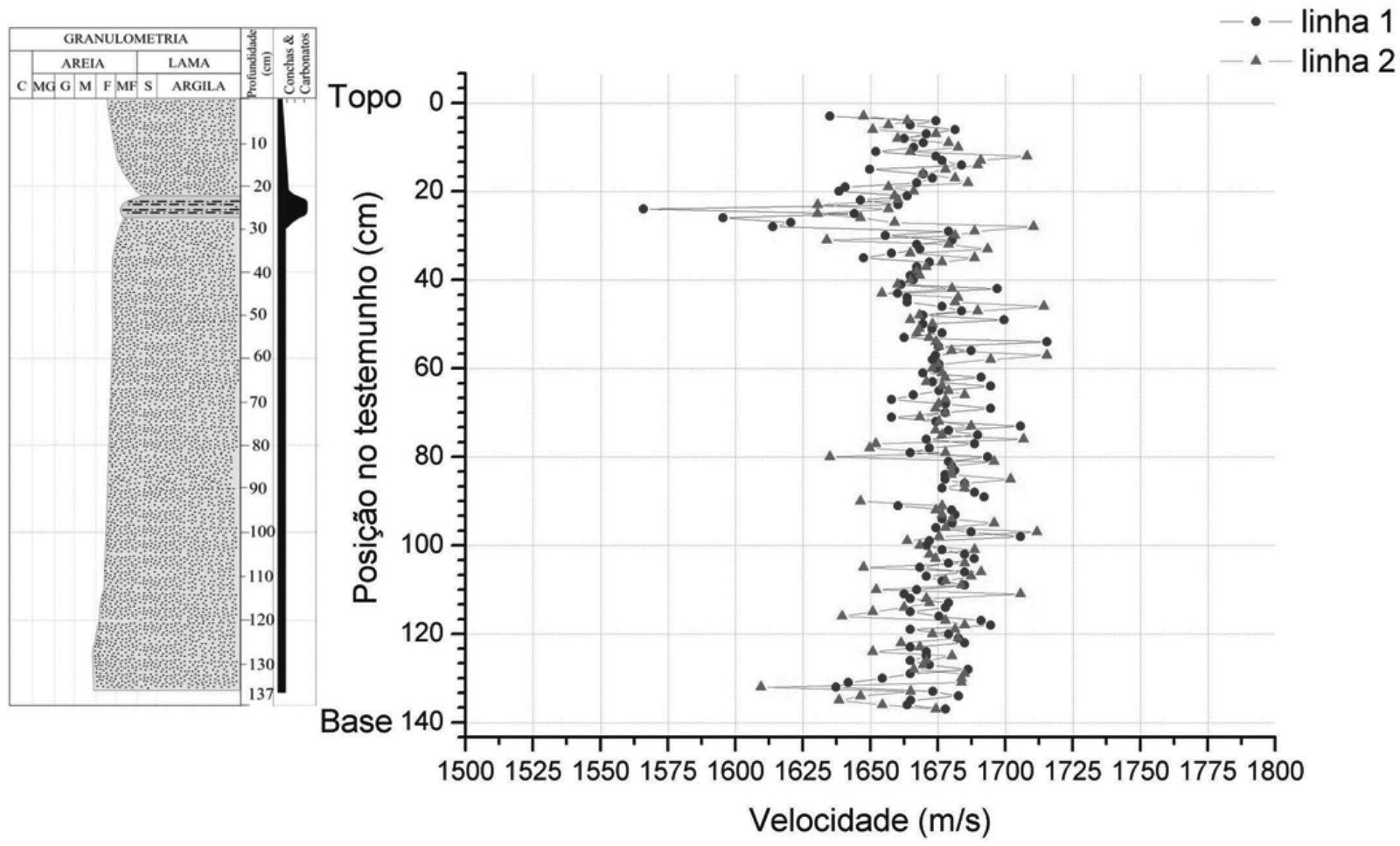

Figura 5 - Testemunho 2. Desenho esquemático da litologia do testemunho e perfis de velocidade do som medidos em planos ortogonais (linhas 1 e 2) ao longo do testemunho.

\section{TESTEMUNHO 2 - COEFICIENTE DE ATENUAÇÃO}
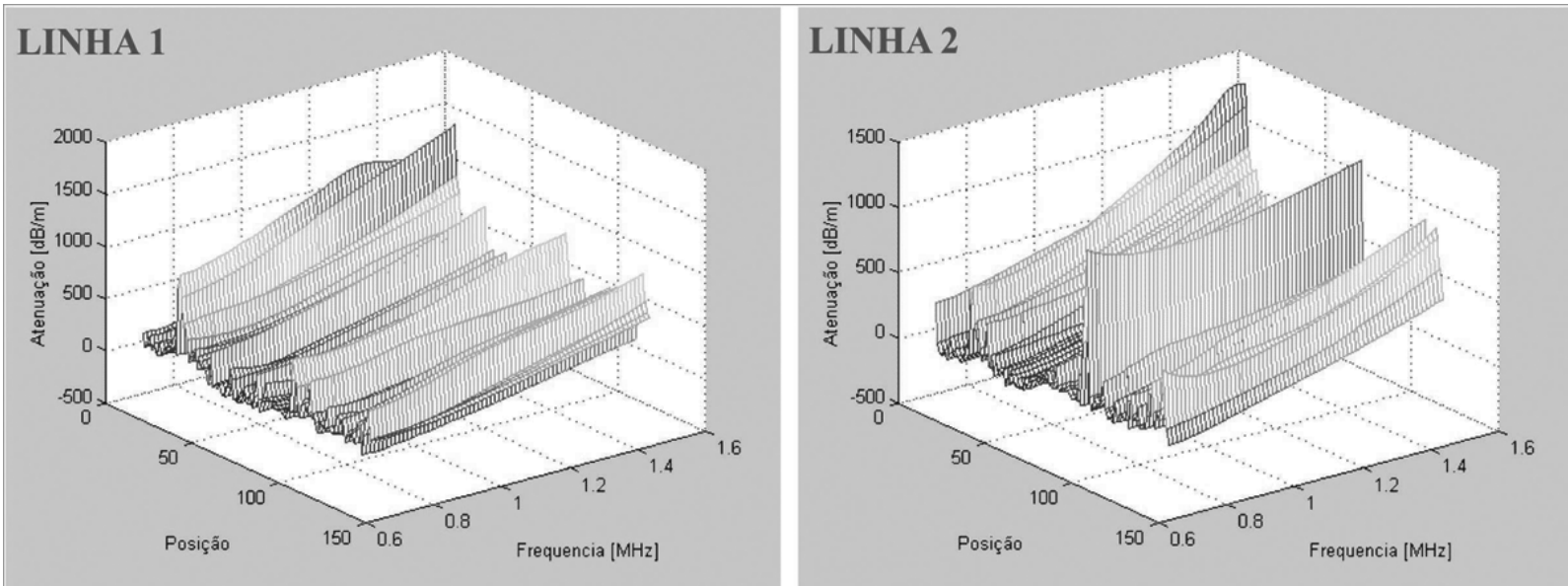

Figura 6 - Testemunho 2. Diagramas de atenuação representativos das medidas realizadas em planos ortogonais (linhas 1 e 2) ao longo do testemunho.

relativamente mais baixos, estando na faixa de 500 a $600 \mathrm{~dB} / \mathrm{m}$. Após $170 \mathrm{~cm}$, uma nova elevação na atenuação é observada, também para 1,6 MHz, onde os valores atingem $1.000 \mathrm{~dB} / \mathrm{m}$. $A$ atenuação se mantém elevada até chegar ao final do testemu- nho, nas proximidades do ponto $200 \mathrm{~cm}$, onde cai para cerca de $500 \mathrm{~dB} / \mathrm{m}$. A linha 1 mostra um comportamento distinto da linha 2, uma vez que se observam apenas dois pontos de valores elevados: um no topo, próximo a $60 \mathrm{~cm}(1.100 \mathrm{~dB} / \mathrm{m})$ e outro 


\section{TESTEMUNHO 7 - VELOCIDADE DE PROPAGAÇÃO DA ONDA $P$}

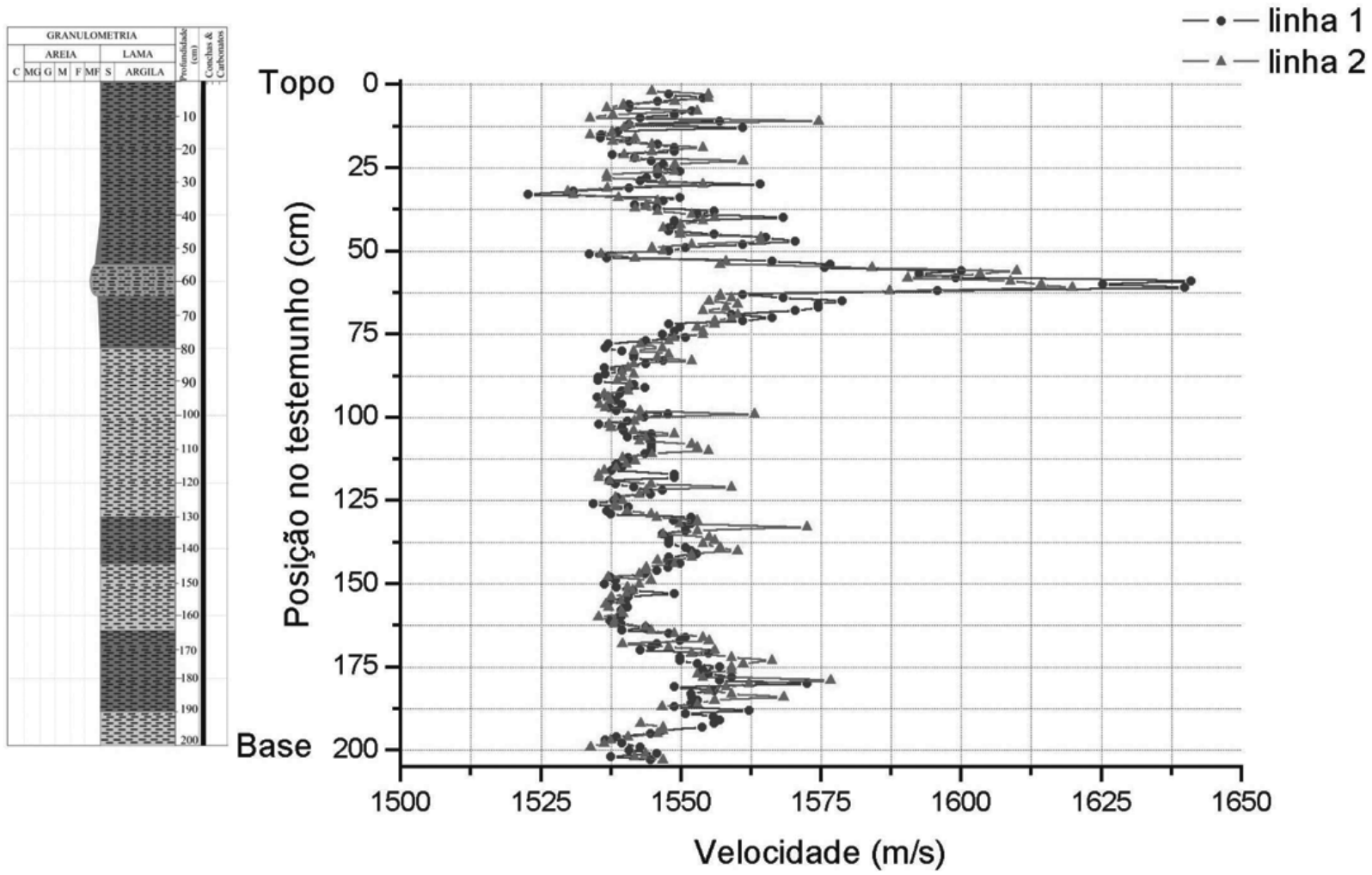

Figura 7 - Testemunho 7. Desenho esquemático da litologia do testemunho e perfis de velocidade do som medidos em planos ortogonais (linhas 1 e 2) ao longo do testemunho.

\section{TESTEMUNHO 7 - COEFICIENTE DE ATENUAÇÃO}
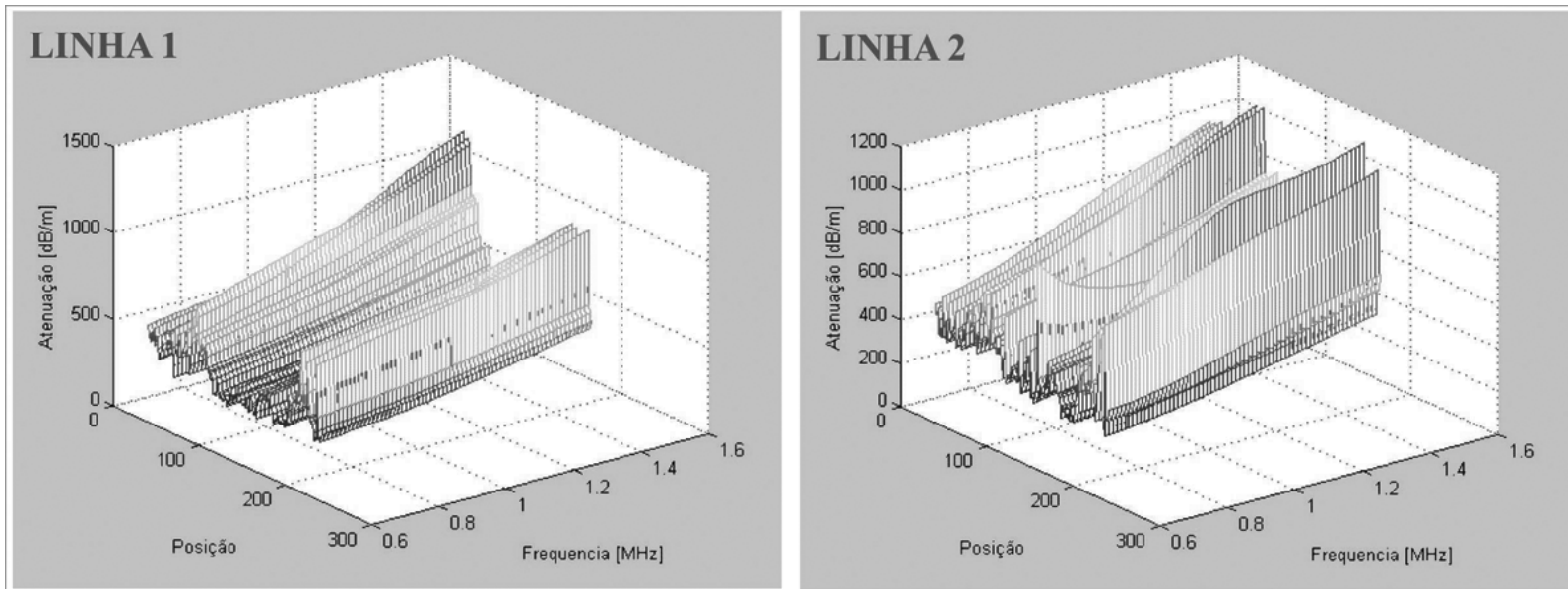

Figura 8 - Testemunho 7. Diagramas de atenuação representativos das medidas realizadas em planos ortogonais (linhas 1 e 2) ao longo do testemunho.

na base, ponto $180 \mathrm{~cm}(800 \mathrm{~dB} / \mathrm{m})$. Os demais trechos registraram valores na faixa de 500 e $600 \mathrm{~dB} / \mathrm{m}$. Resumindo, pode-se afirmar que as medições em lamas consolidadas indicam valores de atenuação de $900 \mathrm{~dB} / \mathrm{m}$ para a faixa de freqüência de 1,4 a
1,6 MHz. As lamas fluidas indicam, para a mesma faixa de freqüência, valores de $550 \mathrm{~dB} / \mathrm{m}$.

Para cada tipo de sedimento dos testemunhos foi estabelecida uma faixa de valores medidos para as $V p$ e para o coeficiente de 
atenuação. A Tabela 1 relaciona as medidas de velocidade e 0 gráfico da Figura 9 apresenta um resumo comparativo da faixa de valores observados.

A Tabela 2 mostra os valores dos coeficientes de atenuação aproximados, para a freqüência de 1,6 MHz. Entretanto, cabe ressaltar que as medidas obtidas não são absolutas, uma vez que esta propriedade varia em função da freqüência. Os valores apresentados significam apenas uma tendência desta propriedade física para a situação específica na qual foi realizada a medição. Pequenas variações na freqüência e até mesmo na posição dos transdutores são suficientes para alterar valores medidos de atenuação em meios viscoelásticos. 0 gráfico da Figura 10 apresenta um resumo comparativo da faixa de valores observados.

Tabela 1 - Faixa de valores de velocidade para cada tipo de sedimento.

\begin{tabular}{|c|c|c|}
\hline Tipo de sedimento & $\begin{array}{c}\text { Velocidade }(\mathrm{m} / \mathrm{s}) \\
\text { valor mínimo }\end{array}$ & $\begin{array}{c}\text { Velocidade }(\mathrm{m} / \mathrm{s}) \\
\text { valor máximo }\end{array}$ \\
\hline Areia grossa & $\left(^{\star}\right)$ & $\left(^{\star}\right)$ \\
\hline Areia média & 1.555 & 1.752 \\
\hline Areia fina & 1.635 & 1.715 \\
\hline Areia lamosa & 1.550 & 1.644 \\
\hline Lama arenosa & 1.492 & 1.639 \\
\hline Lama consolidada & 1.493 & 1.600 \\
\hline Lama fluida & 1.530 & 1.563 \\
\hline
\end{tabular}

(*) Para as areias grossas não houve sinal recebido no transdutor. Toda a intensidade do pulso de ultra-som foi atenuada pelo meio.

Tabela 2 - Faixa de valores de coeficiente de atenuação para a freqüência de 1,6 MHz.

\begin{tabular}{|c|c|c|}
\hline Tipo de sedimento & $\begin{array}{c}\text { Coeficiente de } \\
\text { atenuação }(\mathrm{dB} / \mathrm{m}) \\
\text { valor mínimo }\end{array}$ & $\begin{array}{c}\text { Coeficiente de } \\
\text { atenuação }(\mathrm{dB} / \mathrm{m}) \\
\text { valor máximo }\end{array}$ \\
\hline Areia média & 1.100 & 1.300 \\
\hline Areia fina & 400 & 700 \\
\hline Areia lamosa & 1.250 & 1.750 \\
\hline Lama arenosa & 1.150 & 1.550 \\
\hline Lama consolidada & 850 & 1.150 \\
\hline Lama fluida & 500 & 600 \\
\hline
\end{tabular}

\section{DISCUSSÃO}

\section{Seções dos testemunhos onde não houve recepção do sinal}

No grupo de nove (9) testemunhos diversas foram as seções onde não foi detectado o sinal da onda de US no transdutor receptor. Como a freqüência nominal utilizada foi de $2,25 \mathrm{MHz}$,
0 que implica em um comprimento de onda $(\lambda)$ de aproximadamente $0,711 \mathrm{~mm}$, as partículas com dimensões próximas ou maiores que este $\lambda$ comportaram-se como superfícies "espalhadoras" em potencial. Dimensões de grãos iguais ou superiores a areia grossa $(0,5 \mathrm{~mm})$, principalmente aquelas que têm 0 formato de pequenos planos (conchas e fragmentos), provocam uma intensa atenuação no sinal por espalhamento - scattering (Richardson \& Briggs, 1996; Maa et al., 1997; Buckingham, 2005). Esta situação foi observada em alguns trechos dos testemunhos 1, 3, 4, 6, 8, e 9 (Macedo, 2006).

Outro fator a ser considerado é a presença de gás ou ar trapeado nos sedimentos marinhos. Figueiredo et al. (1996) e Hamilton (1972) citam que a existência de bolhas de gás trapeadas em camadas de sedimento, produzidas pela degradação bioquímica da matéria orgânica, espalham e atenuam os sinais sonoros, causando mascaramento acústico e perda do sinal.

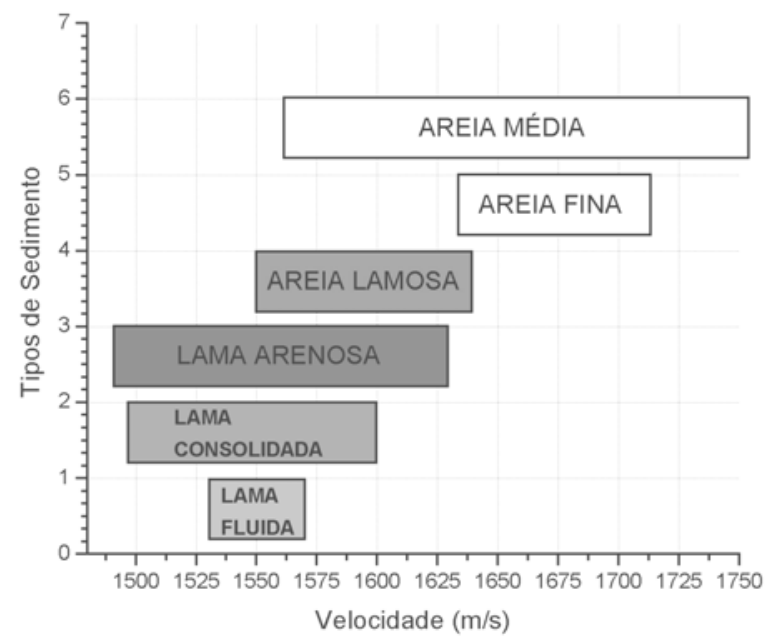

Figura 9 - Faixa de valores de velocidade para as medições nos sedimentos.

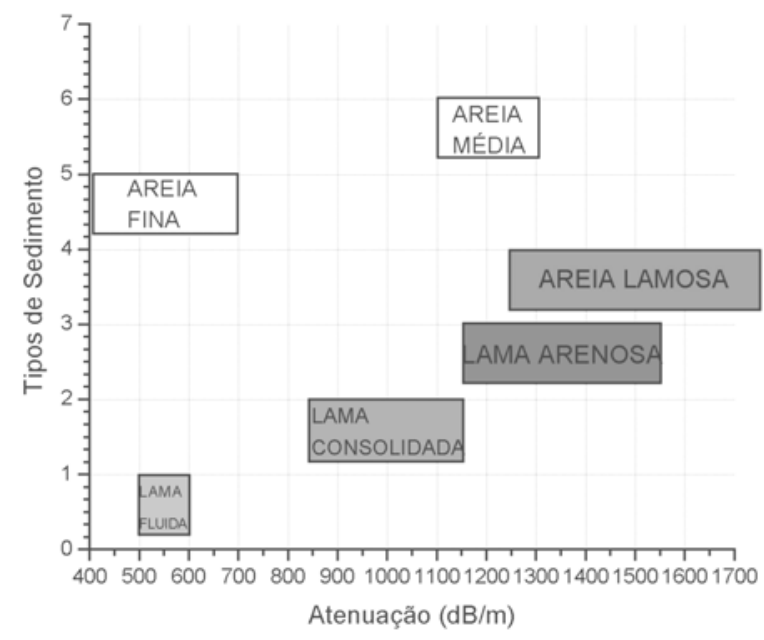

Figura 10 - Faixa de valores observados para o coeficiente de atenuação na freqüência de $1,6 \mathrm{MHz}$. 


\section{Análise dos perfis de $V p$}

No gráfico da Figura 9 as areias (média, fina e areia lamosa) apresentaram velocidades mais altas, quando comparadas com os sedimentos lamosos. Nas areias médias foram medidos os maiores valores de $V p(1.752 \mathrm{~m} / \mathrm{s})$, enquanto que os menores foram registrados na lama arenosa $(1.492 \mathrm{~m} / \mathrm{s})$ e na lama consolidada (1.498 m/s). A lama fluida apresentou medidas de $V p$ intermediárias, quando comparados às lamas consolidadas e arenosas. Estes resultados indicam uma tendência de aumento da $V p$ relacionada a um aumento da granulometria. Tais resultados e a análise apresentada estão compatíveis com os trabalhos de Hamilton \& Bachman (1982); Richardson \& Briggs (1996, 2004); Maa et al. (1997); Ayres Neto (1998); Ayres \& Theilen (2001); Gorgas et al. (2002); Buckingham (2005).

Com relação à faixa de variação entre a velocidade mínima e máxima medida para cada tipo de sedimento (Fig. 9), foi observado que as areias médias, a areia lamosa, a lama arenosa e a lama consolidada, apresentaram uma faixa ampla, enquanto que as areias finas e a lama fluida, mostraram uma faixa mais estreita. Estes resultados podem estar associados aos efeitos de dispersão provocados no feixe de US durante sua propagação no meio, uma vez que foram considerados os valores nas duas linhas de medição (planos ortogonais 1 e 2) de cada testemunho. Tal dispersão pode ocorrer devido à geometria das camadas de sedimento, ao grau de seleção das partículas, como também devido à própria proporcionalidade das misturas dos grãos. Logo, as areias finas e lamas, sedimentos mais homogêneos e menos susceptíveis aos fatores acima citados, apresentaram resultados mais precisos durante as medições. A lama arenosa e a lama consolidada apresentaram valores de $V p$ muito próximos e dentro da mesma faixa de variação, indicando que estes sedimentos têm comportamento semelhante em termos de propagação de onda $P$.

\section{Análise dos resultados de atenuação}

Medições de atenuação em meios viscoelásticos, naturalmente, são difíceis de se obter, tendo em vista a variação desta propriedade em função da freqüência e sua susceptibilidade a ruídos e à anisotropia. Logo, o propósito deste trabalho é relacionar os resultados obtidos nas medições com os diversos tipos de sedimento encontrados, apresentando valores relativos de atenuação e associando as diferenças encontradas às características do sedimento.

Com o resumo apresentado no gráfico do coeficiente de atenuação, em função da freqüência de $1,6 \mathrm{MHz}$ (Fig. 10), foi pos- sível observar que os maiores valores de atenuação, bem como as maiores faixas de variação, foram encontrados nas areias lamosas e nas lamas arenosas. As areias médias e a lama consolidada apresentaram valores intermediários de atenuação, menores que as misturas lamosas e maiores que a areia fina e lama fluida. Para Hamilton (1972), a granulometria e a porosidade são os parâmetros sedimentológicos que mais influenciam a atenuação. Em areias grossas, os grãos são maiores e mais arredondados, a área de contato entre as partículas é menor. Conseqüentemente, a rigidez é relativamente mais baixa em sedimentos grossos quando comparados a finos. Estes resultados são comprovados em experimentos de laboratório e in situ, indicando que a atenuação tem seus valores máximos para areias muito finas, siltes, argilas e suas misturas. Leurer (1997) afirmou que sedimentos de granulometria fina, coesivos, ricos em argila, exibem alta atenuação devido aos mecanismos viscosos de absorção.

Os resultados das medições na areia fina e na lama fluida, onde foram registrados os menores valores, podem ser justificados pelas teorias de Biot (1956a,b), Hamilton (1980) e Stoll (1980). Estes explicam que, em sedimentos homogêneos e com alta concentração de água, as estruturas das partículas finas e do fluido, quando estimulados por uma onda, se movem quase que em fase, não existindo diferença na velocidade que cause uma dissipação viscosa; como resultado, a atenuação é baixa.

Outro dado relevante a ser citado é a linearidade existente entre 0 coeficiente de atenuação, em dB/m, e a freqüência (Macedo, 2006), o que pode ser observado nas Figuras 6 e 8, e também está de acordo com o preconizado por Hamilton (1972, 1979, 1980); Kibblewhite (1989); Simpson \& Houston (2000); Simpson et al. (2003); Buckingham $(2004,2005)$.

\section{Identificação das interfaces entre camadas de sedimentos}

Neste trabalho, principalmente nos testemunhos 2, 4, 5, 6, 7, e 9 , camadas distintas de sedimentos foram claramente identificadas por variações ocorridas nos perfis de velocidade da onda $P$. Maa et al. (1997) obtiveram resultados indicando que grãos de sedimentos finos e grossos mostram propriedades diferenciáveis em termos de velocidade e atenuação de onda acústica.

No testemunho 2, a fina camada de areia lamosa, inserida em um pacote sedimentar de areias finas, foi identificada pela queda na velocidade (Fig. 5). Na areia fina, a faixa de valores de velocidade está entre $1.635 \mathrm{~m} / \mathrm{s}$ (mínima) e $1.715 \mathrm{~m} / \mathrm{s}$ (máxima). No trecho de areia lamosa, o registro sônico mostra uma queda acentuada de valor, atingindo $1.566 \mathrm{~m} / \mathrm{s}$. 0 dia- 
grama de atenuação também registrou uma alteração significativa neste ponto, onde valores de aproximadamente $700 \mathrm{~dB} / \mathrm{m}$ passaram para $1.300 \mathrm{~dB} / \mathrm{m}$.

No testemunho 7, composto por lamas consolidadas e fluidas, as principais diferenças nos acamamentos foram registradas com quedas significativas nos valores da velocidade. Uma pequena camada de lama arenosa, localizada nas proximidades do ponto $60 \mathrm{~cm}$, está relacionada à súbita elevação da velocidade, que atingiu o valor de $1.639 \mathrm{~m} / \mathrm{s}$ (Fig. 7). Essas transiç̧ões também podem ser identificadas nos diagramas de atenuação, com as devidas ressalvas para a faixa de freqüência.

\section{CONCLUSÕES}

As areias (média, fina e areia lamosa) apresentaram velocidades mais altas, quando comparadas com os sedimentos lamosos. Nas areias médias foram medidos os maiores valores de $V p(1.752 \mathrm{~m} / \mathrm{s})$, enquanto que os menores foram registrados na lama arenosa $(1.492 \mathrm{~m} / \mathrm{s})$ e na lama consolidada $(1.498 \mathrm{~m} / \mathrm{s})$.

Nas seções dos testemunhos onde foram encontrados seixos, cascalhos e areia grossa, não houve registro de sinal. Este resultado pode ser justificado pelo espalhamento (scattering) no feixe sonoro provocado por essas partículas.

Os perfis de $V p$ registraram com precisão as variações de velocidade ao longo do testemunho. Estas variações estão relacionadas às mudanças do tipo de material e foram identificadas como interfaces entre camadas de sedimento.

0 diagrama em 3D do coeficiente de atenuação permitiu uma avaliação do comportamento espectral do sinal, no domínio da freqüência, principalmente com relação à linearidade. Este dado facilitou a análise comparativa do modo de propagação da onda para cada tipo de sedimento. Os maiores valores do coeficiente de atenuação, utilizando como referência a freqüência de $1,6 \mathrm{MHz}$, foram encontrados nas areias lamosas e nas lamas arenosas (1.750 e $1.550 \mathrm{~dB} / \mathrm{m}$, respectivamente). As areias médias apresentaram uma atenuação menor que as misturas lamosas e maior que a lama consolidada. As areias finas e a lama fluida registraram os menores valores de atenuação (400 e $500 \mathrm{~dB} / \mathrm{m}$, respectivamente).

\section{AGRADECIMENTOS}

Ao Instituto de Estudos do Mar Almirante Paulo Moreira (IEAPM), ao Laboratório de Geologia Marinha (LAGEMAR/UFF) e ao Laboratório de Ultra-som do Programa de Engenharia Biomédica (PEB) da COPPE/UFRJ, por todo apoio e pela confiança depositada no nosso projeto.

\section{REFERÊNCIAS}

AYRES NETO A. 1998. Relationships between physical properties and sedimentological parameters of near surface marine sediments and their applicability in the solution of engineering and environmental problems. Kiel, 1998. Tese de Doutorado - Erlangung des Doktorgrades der Mathematisch - Naturwissenschaftlichen Fakultät der ChristianAlbrechts-Universität zu Kiel. 125 p.

AYRES A \& THEILEN F. 2001. Preliminary laboratory investigations into the attenuation of compressional and shear waves on near-surface marine sediments. Geophysical Prospecting, European Association of Geoscientists \& Engineers, 49: 120-127.

BIOT MA. 1956a. Theory of propagation of elastic waves in a fluidsaturated porous solid. I. Low-frequency range. J. Acoust. Soc. Am., 28(2): 168-178.

BIOT MA. 1956b. Theory of propagation of elastic waves in a fluidsaturated porous solid. II. Higher frequency range. J. Acoust. Soc. Am., 28(2): 179-191.

BUCKINGHAM MJ. 2000. Wave propagation, stress relaxation, and grain-to-grain shearing in saturated, unconsolidated marine sediments. J. Acoust. Soc. Am., 108: 2796-2815.

BUCKINGHAM MJ. 2004. A three-parameter dispersion relationship for Biot's fast compressional wave in marine sediment. J. Acoust. Soc. Am., 116: 769-776.

BUCKINGHAM MJ. 2005. Compressional and shear wave properties of marine sediments: comparisons between theory and data. J. Acoust. Soc. Am., 117(1): 137-152.

DAVIS A, HAYNES R, BENNELL J \& HUWS D. 2002. Surficial seabed sediment properties derived from seismic profiler responses. Marine Geology, 182: 209-223.

FIGUEIREDO Jr. AG \& MADUREIRA LSP. 1999. Programa de avaliação do potencial sustentável de recursos vivos na zona econômica exclusiva (REVIZEE) - Relatório final dos dados geológicos. Lagemar - UFF e FURG, $58 \mathrm{p}$.

FIGUEIREDO Jr. AG, NITTROUER CA \& COSTA EA. 1996. Gas-charged sediments in the Amazon submarine delta. Geo-Marine Letters, 16: 31-35.

GORGAS TJ, WILKENS RH, FU SS, FRAZER LN, RICHARDSON MD, BRIGGS KB \& LEE H. 2002. In situ acoustic and laboratory ultrasonic sound speed and attenuation measured in heterogeneous soft seabed sediments: Eel River shelf, California. Marine Geology, 182: 103-119.

HAMILTON EL. 1972. Compressional-wave attenuation in marine sediments. Geophysics, Society of Exploration Geophysicists, 37: 620-646.

HAMILTON EL. 1979. Sound velocity gradients in marine sediments. J. Acoust. Soc. Am., 65: 909-922. 
HAMILTON EL. 1980. Geoacoustic modeling of the sea floor. J. Acoust. Soc. Am., 68: 1313-1336.

HAMILTON EL \& BACHMAN RT. 1982. Sound velocity and related properties of marine sediments. J. Acoust. Soc. Am., 72: 1891-1904.

HE P \& ZENG J. 2001. Acoustic dispersion and attenuation measurement using both transmitted and reflected pulses. Ultrasonics, Elsevier Scientific Publishing Company, 39: 27-32.

KIBBLEWHITE AC. 1989. Attenuation of sound in marine sediments: a review with emphasis on new low-frequency data. J. Acoust. Soc. Am., 86(2): 716-738.

KRUMBEIN WC \& PETTIJOHN FJ. 1988. Manual of sedimentary petrography. Classic facsimile edition. Tulsa, Oklahoma, U.S.A. Society of Economic Paleontologists and Mineralogists.

LEURER KC. 1997. Attenuation in fine-grained marine sediments: extension of the Biot-Stoll model by the effective grain model (EGM). Geophysics, 62: 1465-1479.

MAA JP-Y, SUN K-J \& HE Q. 1997. Ultrasonic characterization of marine sediments: a preliminary study. Marine Geology, Elsevier Science, 141: 183-192.

MACEDO HC. 2006. Análise da propagação de ondas compressionais em sedimentos marinhos. Niterói. Dissertação de Mestrado - Departamento de Geologia - LAGEMAR, Universidade Federal Fluminense (UFF), Niterói, RJ. 124 p.

MACEDO HC \& FIGUEIREDO Jr. AG. 2005. Sistema de medição de velocidade e atenuação de onda compressional em sedimentos marinhos. go Simpósio de Geologia do Sudeste, realizado na Universidade Federal Fluminense, Niterói, RJ. CD-ROM.

MACEDO HC, FIGUEIREDO Jr. AG, ARTUSI L \& SOUZA SR. 2005. Análise da propagação de ondas compressionais em sedimentos marinhos e sua aplicação na caracterização das propriedades acústicas do ambiente. $9^{\text {th }}$ International Congress of the Brazilian Geophysical Society, Salvador, BA. CD-ROM.

RICHARDSON MD. 1997. In situ, shallow-water sediment geoacoustic properties. In: ZHANG R \& ZHOU J (Eds.). Shallow-Water Acoustics. China Ocean, Beijing, China. p. 163-170.
RICHARDSON MD. 2002. Variability of shear wave speed and attenuation in surficial marine sediments. In: PACE NG \& JENSEN FB (Eds.). Impact of Littoral Environmental Variability on Acoustic Predictions and Sonar Performance. Kluwer, La Spezia, p. 107-114.

RICHARDSON MD \& BRIGGS KB. 1996. In situ and laboratory geoacoustic measurements in soft mud and hard-packed sand sediments: Implications for high-frequency acoustic propagation and scattering. GeoMarine Letters, 16: 196-203.

RICHARDSON MD \& BRIGGS KB. 2004. Empirical predictions of seafloor properties based on remotely measured sediment impedance. In: PORTER MB, SIDERIUS M \& KUPERMAN WA (Eds.). High Frequency Ocean Acoustics. La Jolla, California, USA. American Institute of Physics, p. 12-21.

SHEPARD FP. 1954. Nomenclature based on sand- silt-clay ratios. Journal of Sedimentary Petrology, 24(3): 151-158.

SIMPSON HJ \& HOUSTON BH. 2000. Synthetic array measurements of acoustical waves propagating into a water-saturated sandy bottom for a smoothed and a roughened interface. J. Acoust. Soc. Am., 107: 2329-2337.

SIMPSON HJ, HOUSTON BH \& LISKEY SW. 2003. At-sea measurements of sound penetration into sediments using a buried vertical synthetic array. J. Acoust. Soc. Am., 114: 1281-1290.

STOLL RD. 1980. Theoretical aspects of sound transmission in sediments. J. Acoust. Soc. Am., 68(5): 1341-1350.

SUGUIO K. 1973. Introdução à sedimentologia. 1 ed. Edgard Blucher Ltda., São Paulo, SP, 317 p.

US GEOLOGICAL SURVEY. 2000. Public Review Draft - Digital Cartographic Standard for Geologic Map Symbolization, prepared in cooperation with the Geological Data Subcommittee of the Federal Geographic Data Committee, Open-File Report 99-430 Online Version 1.0. Disponível em: < http://structure.harvard.edu/ plesch/map\%20patterns>. Acesso em: 27 out. 2005.

\section{NOTAS SOBRE OS AUTORES}

Helber Carvalho Macedo. Oficial da Marinha do Brasil, formado pela Escola Naval (1991). Aperfeiçoado em Hidrografia (1995), em curso na Diretoria de Hidrografia e Navegação. Mestre em Geologia e Geofísica Marinha pelo LAGEMAR/UFF (2006). De junho de 2006 até o presente momento atua no Instituto de Estudos do Mar Almirante Paulo Moreira - IEAPM, em atividades de pesquisas relacionadas à geofísica e à acústica submarina, visando atender às necessidades do setor operativo da Marinha do Brasil.

Alberto Garcia de Figueiredo Jr. Geólogo pela UFRJ (1972). Mestre pela UFRGS (1975). Doutor pela Universidade de Miami (1984) e Pós-Doc. pela State University of New York - SUNY (1990). Professor Titular do Departamento de Geologia, UFF, líder do Grupo de Pesquisa do LAGEMAR, pesquisador 1 CNPq.

João Carlos Machado. Engenheiro eletrônico pela UFRJ (1976). Mestre pela COPPE/UFRJ (1977). Ph.D. pela University of Washington (1983). Professor Titular do Programa de Engenharia Biomédica (PEB) da COPPE/UFRJ, líder do Grupo de Pesquisa em Ultra-som do PEB, pesquisador 1B CNPq. 